"Impact Engineering" or Social Responsibility? - A Debate on the Responsibilities of Academics and Ways to Combine Scientific with Practice Impact

von

Hans Ulrich Buhl, Ulrich Frank, Robert Winter

August 2015

in: Business \& Information Systems Engineering, 57, 4, 2015, p. 279-292 


\title{
“Impact Engineering” or Social Responsibility?
}

\section{A Debate on the Responsibilities of Academics and Ways to Combine Scientific with Practice Impact}

\author{
Ulrich Frank • Robert Winter • Peter Mertens • Wolfgang König • \\ August-Wilhelm Scheer · Hans Ulrich Buhl · Peter Buxmann • \\ Christine Legner $\cdot$ Leena Suhl
}

Published online: 16 June 2015

(C) Springer Fachmedien Wiesbaden 2015

\section{Introduction}

In recent years, our discipline has been subject to a development that affects its core and has already triggered clearly perceptible changes. This development is characterized by two main aspects. The undoubtedly legitimate demand for internationalization - scientific competition does not stop at country or language barriers - creates a need to publish in English. At the same time, Business and Information Systems Engineering is also confronted with increasing and more complex justification challenges. In the early days of the discipline, legitimacy and reputation were achieved primarily through "practice impact" (e.g., successful application projects) and high numbers of students. Under the influence of international conventions, another reputation mechanism has gained significance in recent years, namely "scientific impact". Since scientific impact is a multidimensional construct, more or less simplistic metrics have been proposed to capture it. These are mainly based on the result of scientific work most easily quantifiable, namely publications. Even worse, the evaluation of publications itself is often reduced to the assessment of its publication outlet's reputation. Top-rated journals are mainly found in the Information Systems discipline (i.e., not in the more "technical" sub-disciplines

Prof. Dr. U. Frank

University of Duisburg-Essen, Chair of Information Systems and Enterprise Modelling, Universitätsstr. 9, 45141 Essen, Germany

e-mail: ulrich.frank@uni-due.de

Prof. Dr. R. Winter $(\bowtie)$

Institute of Information Management, University of St. Gallen, Oberer Graben 21, 9000 St. Gallen, Switzerland

e-mail: robert.winter@unisg.ch of BISE), as the Information Systems discipline has undergone considerable pressure to justify its scientific significance at business schools for more than 30 years.

While the transformation of BISE seems to be inevitable and scarcely unsettling from a distance, many consider its consequences to be dysfunctional. Young scientists are often advised to focus on measurable scientific impact. Hence, they feel highly pressured to publish in the few Information Systems journals which promise to create the highest reputation. The behaviorist orientation cultivated in most of these journals significantly changes research objectives and methods from what they used to be in BISE. It can already be observed that certain topics of BISE that used to be indispensable in teaching and for practice impact, have disappeared from the research agenda. In addition, researchers lose interest in traditionally important discussion forums such as conferences or specialized workshops, and specialized journals often receive submissions only after these were rejected by supposedly toprated journals. Ultimately, the increasing focus on measurable publication results threatens the attractiveness of BISE research, because the interest in knowledge creation is being more and more replaced by an opportunist orientation to supposedly "publishable" topics.

The transformation process outlined here matters to many of us, especially those who are considering an academic career. It is connected with the fundamental question of how university professors in our discipline should shoulder their social responsibilities on the one hand, and how they should respond to the increasing use of indicators for the comparative evaluation of scientific performance on the other. In our opinion, the classic ideal is not an increasing focus on individual impact dimensions or even publication channels, but the combination of two interrelated contributions, i.e., 
- teaching advanced concepts and methods. This includes satisfying the demand of today's and tomorrow's organizations. From a societal point of view, there is urgent demand for graduates who take on a creative and responsible role in the digital transformation. For this purpose our students need to develop expertise both with respect to the conceptualization of information technology and to managing digitally enabled organizations.

- research that is focused on superior knowledge. This requires appropriate instruments and common values for guiding scientific competition. That includes convincing approaches to evaluate and document particular contributions. While currently journal reputation is an accepted proxy for a contribution, many alternative metrics (which could be, e.g., based on actual re-use of findings) are emerging.

In the context of the Wirtschaftsinformatik 2015 conference in Osnabrück, two panel discussions were held which addressed the issue of impact with different focuses. In the first panel discussion (moderated by Ulrich Frank) with the deliberately provocative title "Impact Engineering or Social Responsibility", Peter Mertens and August-Wilhelm Scheer, as two of the founding fathers of BISE, demanded BISE research to be primarily (even if in different ways) oriented towards the requirements of BISE practice. Hans Ulrich Buhl, rather inclined towards practice-oriented research, and Wolfgang König completed the round. Both have in the past argued for strengthening the scientific impact of BISE.

The following three contributions represent an ex-post view of three participants of this panel. Peter Mertens advises against the uncritical use of evaluation criteria that are limited to measurable publication outcomes. He also regards an opportunistic orientation toward topics and methods promoted by Information Systems as misleading since it would compromise the discipline's ability to support organizations and society in general. Wolfgang König takes a different stance. He recalls the times when "Wirtschaftsinformatik" was widely restricted to publications in German and ambitious reviewing standards were missing. Since research in our field needs to aim at international recognition, he demands to follow existing patterns of reputation, i.e., to aim at publishing in highly ranked journals. According to August-Wilhelm Scheer researchers in our field need to have elaborate knowledge about business practice and should collaborate with ICT companies in order to drive progress. At the same time he emphasized the pivotal relevance of teaching for creating impact in practice. Hans Ulrich Buhl proposes to focus on highly ranked journals and to not shy away from "impact engineering". However, he suggests to complement it by a strong focus on research that is beneficial for practice, especially by joint projects with business firms.

What are the lessons we might learn from the panel discussions? Similar to colleagues in Information Systems, many researchers who feel more associated with BISE are concerned about the current state of their discipline. While some seem to cope with current challenges, others quarrel with them. But no matter whether the current state of our discipline is regarded as a crisis or not, we believe that a discourse about the future of how we do research and how we organize scientific competition, communication and documentation is not an indication of weakness. Instead it could demonstrate our willingness to re-think our conceptions of research as well as teaching - an attitude that many of us recommend to organizations to be prepared for digital transformation. For this purpose, it might be a good start to recall essential academic virtues, i.e., to strengthen a culture that emphasizes criticism, freedom and profound thinking as values of their own - and to strengthen the university as the primary place to understand problems, develop sophisticated solutions and elaborate ideas of a future that is enabled by information technology innovations. We might then challenge some of the assumptions that characterize the current debate, e.g., that there is a necessary conflict between social impact and academic impact or, in other words, between rigor and relevance; or that traditional journals and peer reviewing processes are the best way to evaluate and disseminate scientific knowledge. Against this background we hope that the panelists' positions contribute to an inspiring discourse on the future of our discipline and our work as academics.

\section{Part One}

\subsection{Let Us Shift Scarce Resources!}

The situation of Wirtschaftsinformatik (WI) as a branch of science is not in every respect satisfactory. In the Staufenbiel-ranking, which indicates the employers' demand for graduates, it forfeited its pole position and fell behind Computer Science, Management and Industrial Engineering - just in the so-called "era of digitization". Business \& Information Systems Engineering (BISE), the flagship among the WI-journals, has lost approximately half the subscribers compared with its former peak level. The participation of scientists and practitioners in our congresses has considerably declined in relation to the growing number of faculty and IT specialists. Only few representatives of WI are still members of influential German committees that organize the cooperation between science, business, and public institutions. 
To interpret these trends as indicators of a crisis would be exaggerated. However, they are early warning signals. One general cause are problematic evaluation criteria which may suit other disciplines such as biomedical sciences or economics but not a profession which has the mission to use the progress of IT for business purposes and thus help the economy and the society. Particularly we should question an unduly strong and uncritical orientation of WI towards the research goals and methods of the IS discipline in the Anglo-Saxon countries.

Thesis 1: The present practice of evaluating researchers of WI primarily by counting publications of a certain type in selected journals provokes capacity bottlenecks, takes up a considerable share of the working time, is connected with many further drawbacks like the inducement to "Impact Engineering", and does not guarantee a fair decision.

Since approximately 3 years I keep a record of weaknesses regarding the prevalent criteria to evaluate and rank university professors. Now it comprises 38 entries. Most I took from the technical literature which meanwhile is rather comprehensive and controversial. I also added some experiences of my own.

Due to space limitations I here pick two aspects only:

- Not only authors suffer from bottlenecks but also a lot of institutions. The president of the German Research Foundation (Deutsche Forschungsgemeinschaft) recently published alarming data on the work overload of reviewers. My successor, Professor Kathrin Möslein, suddenly had a waiting line of more than 1000 reviews and comments. This situation leads to numerous risks and side effects, e.g., what in game theory is called the "bottleneck poker". It seems that some professors even delegate the review process to their assistants which is not the idea of peer-to-peer reviewing.

- Colleague Disterer has published a thorough analysis of the literature on IS and WI. He found an average of 2.9 authors per paper. In my private statistics I arrive at slightly more than 3.1. To attribute an article to a single author is comparable with the attempt to identify Germany's best rower out of eight athletes in the boat which won the Olympic gold medal. This is a kind of knock-out criterion for the evaluation or ranking procedure.

Thesis 2: The weaknesses that I mentioned in thesis 1 are connected with the selection of research focuses. They prevent WI to adequately deal with present and future problems of the firms, the economy and the society. So a loss of relevance is almost inevitable.

Preliminary note: The following statements should be apprehended as observations of a general tendency. They do not exclude that single scientists deserve merits. I say this also referring to Leena Suhl and the other colleagues who will participate in the subsequent panel.

I choose two examples:

- The German National IT Summit: Only our colleagues Krcmar, Oberweis, Picot and Scheer are members. This makes 3 out of 213 persons.

- Council for IT Infrastructures: 0 out of 24 persons are colleagues from BISE.

We have neglected the IT solutions and far reaching automation projects in important fields which are essential for our economy and society, e.g., farms and the so-called digitized building models and projects.

Industry 4.0 is not, as often depicted, a bipolar subject for computer scientists and mechanical engineers. A triangle including management/WI would be the appropriate framework. For example I bear in mind the big challenges in connection with worldwide standards of intercompany information exchange or of negotiations between the computers of different firms in a supply chain which in the future might be delegated to software agents or multi agent systems.

Generally it is an important mission of WI to prevent the impending descent of our country as a consequence of its disastrous demography. However, presently we see the opposite: There are modifications of business processes which entail that the computer no longer helps man, which is an important goal of WI, but vice versa. An example is the IBAN (International Bank Account Number). Sometimes we call it ironically "IBAN the Horrible", remembering the famous Russian tsar Ivan the Horrible. The number was invented for payment transactions within the EU. Instead of the former 14-18 digits and letters, the IBAN needs 22 for national and more than 30 for international payments. Another example are questionable practices which are the contrary of what we do when teaching our students IT-supported document management. After a minor revision of my theft insurance I received five letters with a total weight of $750 \mathrm{~g}$. In the envelopes there was a text in tiny print pretending that it would be more costly for the insurance company to avoid redundant letters than to pay the postage for five letters! Meanwhile I have a collection of a dozen envelopes with slightly different texts, sent by various firms. Other disciplines like Medicine would start a discussion about such a dubious trend and protest in public.

Thesis 3: IS with its present concept should be less of an antitype of WI. It would be advantageous for us to orientate ourselves more towards traditional disciplines like mechanical engineering, or vehicle manufacturing, or software engineering.

I guess, for example, that the "science of construction", called "Design for X" - where $\mathrm{X}$ is the set of parameters 
which has to be optimized when goals conflict and at the same time regarding technical, business, economic and societal criteria - is far superior to the Design Science proposed by IS authors. "The knowledge of engineers (including that of software engineers) expresses itself more in products than in papers" (Michael Mahoney). In the last years I had the opportunity to discuss the convergence of IS and WI with several colleagues from IS. I remember a question of Carrol Saunders, longtime editor-in-chief of MIS Quarterly, when I asked her what WI might learn from IS: "Why do you want to change since you are successful?"

I recommend to use two well-established methods of business management when it comes to select subjects of teaching and research:

- Define those primary objectives of society and of economy where WI can contribute. Use a hierarchy of goals comparable, e.g., to the Du Pont tree in order to identify a demand pull for special solutions.

- Reflect where the technology push may help to meet the demand.

To provide the necessary capabilities and capacities, I would shift the weight of criteria for the selection of WI university professors from the so-called impact factors to practical experience in building application systems and information management with private firms and in public administration.

\section{Peter Mertens}

\subsection{Scientific Impact as Social Responsibility}

My mindset was shaped by experiences in the last 25 years. In the end of the 1980s, I was appointed speaker of the then founded focal research program "Distributed Business Information Systems" of the German National Science Foundation (Deutsche Forschungsgemeinschaft, DFG) which ran a small two digit number of research projects spread across the Federal Republic of Germany. Alongside the topical themes, the DFG requested explicitly that this program should profoundly promote the international exposure of our research results. We all on today's podium remember our rumbling and laborious start of this endeavor. In those times, we were - with occasional exceptions used to publish our research results in German-speaking media (mostly conferences, but also journals); only rarely did we encounter double-blind reviews. We were rather "self-sufficient" on our "German language island" - and this was of course true not only for the German IS researchers. In general, we have not sufficiently marketed our perception of important things to the international world - of course in English.
No wonder that the internationally renowned IS research contributions from Germany were sparse. What is more, during high-ranked international conferences (for instance ICIS) in the 1990s we frequently encountered hostilities of internationally acknowledged colleagues with German roots who complained that they had been mobbed out of Germany because - as they said - the "Germany Inc.," the insider relationship among German-speaking researchers, was a superior argument for being appointed a chair rather than - internationally renowned - research quality. And I recall vividly our "processions" to famous or ambitious Anglo-American colleagues asking for placing an edited volume with our research results in their editional book series. In the end we were successful - and at that time some of us made ourselves acquainted for the first time with the voluminous international body of knowledge and in the following wrote a high-quality article presenting research results in English. Two figures may illustrate the severity of the - of course rightly requested - paradigm shift: Not until 1995 was the double-blind review system introduced into our German language IS flagship research journal WIRTSCHAFTSINFORMATIK - and the decision in the editorial board was only taken by a majority of one single vote.

This originally tender plantlet of good, internationally acknowledged IS research quality in German-speaking countries has meanwhile even further improved and thank God - grown into a large field of sturdy bushes with quite a number of outstanding groves. And our task for the next decade is to further develop this symbol of our improved reputation and appreciation from a lot of renowned international colleagues to create a clearly visible forest. These illustrations indicate that we have made quite substantial progress in the last 20 years but we still have not fully exploited our potential - and we are not yet sufficiently represented in the world champions' league of publications. Again looking back briefly, we have indicative for a phase 1 - during the last 20 years increased the percentage of accepted German contributions to the ICIS by an (estimated) factor 10. The placement of research results in international top journals (phase 2: IS journals) has also increased, but lags a little behind which is a logical second step. And a third phase will look for international IS publications in broadly positioned, general economics journals. After all: the laid foundations are able to bear heavy loads.

Against this backdrop, the title of our today's panel "Impact Engineering or Societal Responsibility" seems questionable. Do we really exercise societal responsibility of a researcher without sufficient impact - and as we have seen: internationally acknowledged impact? I have learned in the last two decades that we certainly may criticize the one or the other exaggeration in the international double- 
blind peer-review. But the vast majority of expert reports, written by renowned colleagues around the world in the course of the double-blind review, request as a standard that an article has to discuss the latest knowledge on theory building and on approved procedures to gain new knowledge (also in a sense that a fellow researcher may repeat that (kind of) experiment with the same antecedents and ends up with the same research results). This methodological rigorousness which is sometimes criticized for being too laborious and time-consuming is intended to prevent us from stating fictitious truths, and I think everyone of us knows cases where this principle was violated - not because, for example, a new technology resulted in a disruptive organization, but because a literally equal institutional setting of applying an information system in a social environment was not sufficiently deeply analyzed in the first place. Additional costs arising from such faulty research results are often very high - thus it is also a societal responsibility to avoid these. In this context, another illustrative example may highlight the quality request: In the German athletics championships the performance peak as well as the performance width amongst the top scorers are smaller than in the world championships.

These are all grave arguments for why we cannot afford - since more than two decades already - to "cultivate a publication hemisphere only according to our local IS requirement". Rather, we have to adapt to international usances - to the "world market". Actually, the opposite approach makes sense: Apparently, we enjoy such a lot of IS research quality options in Germany that it is our societal duty to share our knowledge and our (profoundly derived) novel insights with the international - and thus also national - community.

Another often heard argument against the international double-blind peer-review states that the screening of rigorousness causes a loss of attention to the real-world application of a new methodology. Yes, we all know such cases. However: In recent years an increasing number of ambitious universities in German-speaking countries request as conditio sine qua non internationally high ranked publications, as do for example top researchers of other scientific disciplines in the DFG or in other research support organizations when these institutions allocate research funds. And: The superior body in the Federal Republic of Germany to comment fundamental science questions - the Wissenschaftsrat - stated already more than ten years ago that a very good research result is based on a successful application in the intended environment. These very good research results thus are based on both a profound methodology as well as on the applicability in practice - and the majority of international top journals go for this dual goal. And I also confess to request rigorousness and applicability - in this order, because we should not waste the precious time of researchers and managers with unsound research practices and thus unjustified results.

And what are our answers to researchers complaining about weaknesses in international peer-review systems, for instance with regard to a limited appreciation of midEuropean solution approaches to complex problems by the Anglo-American "old bulls" and their followers in international editorial boards? Raising the moral pointing finger and requesting from editorial board members to change their habit is not productive - as always in life. Again, the opposite approach makes sense. Rather than - after decades of negligence - asking these members to change, we have to change in the first place. How? The logical approach is to establish more German root authors in the high-calibre editorial boards. How to obtain such acknowledgements? First you have to place one or several top notch research articles in these top journals - i.e., you have to convince the existing editorial board. Here, some colleagues object that a researcher first has to adapt to the given culture in order to later be capable to fight it, but instead, in the first step, this strengthens the habit that should be changed. The objection is both true and unproductive. We have been acting only on the sidelines of the international publication circus for decades, so this is the price that today's German researchers have to pay. And - as with every investment: You first have to spend additional resources before you earn the payback (hopefully with a sustained surplus) in future periods, and the substantial increase of appreciation for research articles of German (speaking) origins over the last two decades is a visible form of this payback.

To translate these insights into an imperative: Let us as the German (speaking) IS community encourage our top scorers in internationally renowned journals and support them to accept membership offers in the respective editorial boards; and then we must beg these colleagues to reform the international peer-review system as acknowledged "insiders". This is not an easy path, but it is the only one I can see to complete the process to overcome the deficiencies that our fathers have originated and that we also have strengthened over many years. And this does not mean that all others who have not yet been successful in placing a research article in an international top journal must not do anything: I call for their active support of the others, for our common advantage.

We have been - this is my estimate - more than $60 \%$ successful making up leeway, this bolsters us up. We must not stop now - rather we have to resolutely continue on that way, also because the international competition is further increasing.

Wolfgang König University of Frankfurt 
2.3 Collaboration with Business Firms and Teaching as Prerequisites of Successful Research and Scientific Impact

\subsubsection{Introduction}

With regard to the question of whether information systems should play a more formative role or take an observational, analytical, and evaluative perspective in the use of ICT in companies, I firmly stand on the side of a design science research. I have pursued this approach since my professorial career started in 1975. Since professionally deployable (software) products cannot be developed at a research institute, but, at best, only ideas regarding them and prototypes, I founded the software and consulting firm IDS Scheer AG in 1984. I built it up to a 3 300 employee-sized company with a presence in about 50 countries, successfully listed it on the stock exchange in 1999 and sold it to Software AG in 2009. The biggest success was certainly the development of the ARIS software system, which is used worldwide, in particular by large enterprises, to optimize their business processes. This is based on the ARIS concept that I developed as part of my research. At the same time, I continued in my role as Head of the Institute for Information Systems at the University of Saarbrücken until I became a professor emeritus in 2006. My remarks are thus based on my experiences as a researcher and entrepreneur in ICT industry.

\subsubsection{Thesis: A Design Science Researcher and Teacher Must Have Practice-Orientated Knowledge}

This statement is actually self-evident. It contains certain challenges, as the researcher has to recognize what knowledge is practice-orientated and what is not.

Therefore the researcher needs insights into practical business strategies and links between the ICT development and its influence on business processes. The perspectives of theory and practice can differ significantly from each other in this regard.

A few weeks ago, a scientist friend of mine, who has been working on scheduling problems for the last 35 years, confessed to me, expressing a certain disappointment, that he had put the wrong focus for his whole research career. His ambition was to optimize shop floor problems and he constantly strived to link his research to practice. Finally, he had to admit and to realize that for practice it is more important to operate a factory on an organizational basis with ERP (Enterprise Resource Planning) and MES (Manufacturing Execution System) software than to deploy more elaborated optimization algorithms whose results quickly become obsolete and are not professionally supervised. Thus, there was a huge gap here between expectations and reality.

Therefore it isn't just sufficient to have a practice orientation. Instead the key is to take up practice-related problems and to direct your area of research in this direction. Researchers should thus have dealt with the conceptual development of MES systems, and should attempt to introduce (possibly simplified) optimization approaches there, rather than only dealing with algorithms on an isolated basis and believing that his theoretical examples would already be convincing enough. After becoming a professor emeritus, my colleague is now working on optimizing share portfolios.

\subsubsection{Thesis: Collaboration with ICT Companies Is Necessary for Creating Development}

The saying "software eats the world" illustrates this perfectly. Software governs both the world and, in particular, the business processes in companies. So, if a researcher has developed a new idea to improve decisions or business processes and wants to have it practically implemented, it is mandatory to have it incorporated into a software product. To this end, he can try to convince existing software providers to include his idea in the next release of their software. In order to achieve this, a competent contact person must be identified within the software company; this already raises some difficulties. However, the most complicated part is to convince him of the benefit of the idea and to kindle his willingness to approve an adequate investment. As a rule, software companies already have a long line of development requests from internal developers, as well as from existing clients, and these have a higher priority than new research ideas.

Also my ARIS development was rejected by existing software companies when I initially presented my concept to them with the aim of implementing it. They could not gauge its utility for customers and the investment risk was too high for them. However, as I was confident about my idea, I successfully developed the software at my own startup company IDS Scheer AG.

Both routes, convincing an existing software company and founding a start-up company, are difficult but essential for the practical implementation of an idea. To do this, the researcher does not need to found the start-up company as a one man show, instead he can inspire doctoral candidates or students to participate with him. It is, however, helpful to use his name for the company. If the product is finished, it can be easier to build up a partnership with an established software company, as investment decisions can now be dispensed with.

If contact is successfully made with a large software company, this offers the researcher a variety of 
development possibilities. If he makes an appearance at the company's international events, he opens up new communication channels to users who would not be accessible to him in the world of scientific publications.

For instance, during the 1990s I was able to present my ARIS ideas at events organized by SAP all over the world. Because the international scientists in the field of information systems had underrated the success of the ERP systems, I had a USP. At that time, business administration and information systems were occupied more with decision-making problems and had not recognized the significance of company-wide integrated application software and the standardization of business processes by means of ERP systems. Business schools in the USA could not realize the success of SAP, for instance. However, as companies insisted on students being trained in ERP systems, the academic teachers urgently had to build up the knowledge. As a result, I was a frequent guest speaker at US universities.

\subsubsection{Creating Development by Means of Applicant- Relevant Teaching is Even More Important than Application-Oriented Research}

In order to transform research ideas into successful software, you need relevant research findings, luck, persuasiveness and entrepreneurial courage. These qualities are rarely combining by themself. Therefore, teaching is key to enable developments. The aim here is to impart the kind of capilities to the students that will enable them to apply the course contents within their careers, obviously along with the mandatory basic knowledge. Some criticism of the current stream of empirical research in information systems is necessary here. If research and teaching are still supposed to be related, this raises the question of what knowledge about empirical statistical procedures a future IT manager will need. Although the delicate empirical findings about the behavior of IT users may be totally interesting, they are of little help to an IT manager in a practical setting. For this reason, knowledge about application architectures, database systems, new business models, etc., is more important. Training on practical SAP systems, for instance, is by far more helpful for someone's future career. By now this has also been recognized by many academic teachers, who eagerly take up the offer from software providers to use their products free of charge in teaching. The academic teacher also has several possibilities here for discussing suggestions for improving the software with the students, so that they can develop these ideas further after they graduate.

\subsubsection{Research is Never Free, but Researchers Must Recognize and Use the Routes for Influencing Research Institutions}

Researchers are evaluated by reviewers through exams, appointments, research applications, submissions for publication etc. These reviewers have their own measures of value and generally apply them with regard to the candidates. This is why a researcher is also tempted to push himself into mainstream research. If publications in highly renowned journals are highly rated, in the interest of their careers, researchers will apply the kinds of research topics and methods that they think correspond with the research direction of these reviewers.

If a researcher wants to change these directions because they do not correspond with his scholarly field, he can ignore them and do without acceptance of his work, or try to influence the acceptance. In order to achieve this, he must make a lot of effort by working in the appropriate committees. This means, in effect, that he must become a reviewer, publisher, political advisor for research programs, etc. himself. This requires a lot of time and financial cost.

\subsubsection{Each Researcher Must Find His Own Way}

Established researchers can easily declare idealistic values and advise young researchers to look for their research field independently. In their application process, however, the latter are faced with the current mainstream, which places a negative evaluation on differing ways of working. So what should a young researcher do?

$\mathrm{He}$ could initially adapt to the mainstream in order to achieve certain goals in his career, for instance a professorship, so that he can pursue his actual interests once he has achieved more (also financial) independence.

Another possibility is also to initially reject a research career, gain status in the research landscape as well through entrepreneurial innovations (founding a start-up company) or influential management activities and then go back to the academic world.

A third route is to look around for possibilities all over the world, in order to find a research facility that corresponds with one's own ideas.

A good decision-making tool can be the path of life of Albert Einstein, who was initially not appointed as a professor by the ETH Zürich, and instead became a midlevel employee at the patent office in Bern, continued his independent research there and after his international success, was showered with offers of appointments from established universities. Albert Einstein was also open to a 
design science approach. For instance, he owned a patent for a gyroscopic compass. In the end, his research changed all of our lives.

August-Wilhelm Scheer Scheer GmbH and AWS-Institut für digitale Produkte und Prozesse, Saarbrücken

\subsection{Impact Engineering and Social Responsibility}

\subsubsection{Introduction}

The discussion in Osnabrück about impact engineering or social responsibility showed that many members of our community are unhappy with the status quo, and that numerous young and untenured researchers are in a dilemma in the midst of a wide range of different challenges.

Some older colleagues with good and secure pensions advise them not to care about impact in highly ranked journals. They measure the impact of journals by the number of German print subscribers - in the era of internationalization and digitization. They ignore that the perennial downtrend in the number of print subscribers of and submissions to German journals has already existed for 25 years and was caused by both sticking to the German language for decades on the one hand, and the lack of a good digitization strategy on the other hand. Those journals which successfully managed both an internationalization and digitization strategy were able to stop the downtrend even with print subscriptions and submission and improved international reach by exploding downloads, citations and impact factors.

Therefore, a discussion about the identity and the development of our Business and Information Systems Engineering (BISE) community is inevitable!

The so-called triple strategy from 2009 to 2014 can serve as an example for internationalization and digitization of a scientific journal. It intended to transfer the advantages of the journal WIRTSCHAFTSINFORMATIK and its topics for the German-speaking area into the international area by means of its English speaking twin issue Business \& Information Systems Engineering (BISE). At the same time, Wirtschaftsinformatik \& Management $(\mathrm{WuM})$ was supposed to address German readers in the industry. As a result the perennial downtrend in number of submissions and subscriptions could be stopped, the impact factor of BISE quadrupled, and the number of downloads quintupled within 5 years (Buhl 2013).

With respect to internationalization and digitization it was interesting to observe that the number of downloads of BISE at the end of its 1 year 2009 amounted to $75 \%$ of the level of WIRTSCHAFTSINFORMATIK at the end of 2008, the journal's 50th German year, and more than $75 \%$ of these downloads originated from non-German-speaking countries.

All in all, articles from BISE/WIRTSCHAFTSINFORMATIK are meanwhile downloaded more than 12,500 times per month as compared to less than 1500 in 2008. Also as a result of the new strategy of Martin Bichler and his team, these success factors of the journal have been further improved impressively and, e.g., in 2014 the number of submission to BISE more than doubled compared to the time before the triple strategy.

Continuously improving the quality of the content on the one hand and further enhancing the indicators discussed above on the other hand are in my opinion the important success factors of a scientific journal in the era of internationalization and digitization today and in the future. Measuring the impact of a journal by the number of German print subscribers is, however, an indicator of the day before yesterday.

In the following, I will briefly sum up my statements of the discussion in Osnabrück. For an in-depth discussion about the future of our BISE community and the challenge of connecting academia and industry, I would like to refer to my BISE-editorial "On Dinosaurs, Measurement Ideologists, Separatists, and Happy Souls - Proposing and Justifying a Way to Make the Global IS/BISE Community Happy" (Buhl et al. 2012a) and the JAIS-paper "Business and information systems engineering: a complementary approach to information systems - what we can learn from the past and may conclude from present reflection on the future" (Buhl et al. 2012b). Both papers discuss different ways of how to combine research with practical impact, and how to use the North American Information Systems (NAIS) community and the Business and Information Systems Engineering (BISE) community from the Germanspeaking countries as reliable proxies for this discussion. Thus this article constitutes a mainly shortened, but also partly enhanced version of these papers.

\subsubsection{Impact Engineering and Social Responsibility Is the Duty of Every Single Researcher}

In my opinion, the title of the discussion in Osnabrück is misleading. The decision of a BISE researcher is not whether to practice impact engineering or social responsibility, it's a decision of how to combine impact engineering and social responsibility. Every researcher needs to find his convex combination of the two. I am convinced that the BISE (and also the NAIS) community should strive for a future where it develops strong contributions for both theory and industry. This would create an environment where the vast majority of the community members characterize themselves as happy souls, and where the community is not just driven by changes in its ecosystem, but is 
also in a position to drive change. To do so, the BISE community has to keep in mind its own strengths such as the interaction with industry, which increases the practical relevance of the research, generates higher attractiveness for academic offspring, and leads to more stable student enrollment rates. On the other hand, the BISE community can learn from the NAIS community's commitment toward research excellence, yielding stronger contributions to theory, higher research quality, and more publications in top-ranked journals. Every researcher needs to find his personal convex combination of various complementing strengths!

\subsubsection{Diversity Instead of "Mile Deep/Inch Wide Lonesome Cowboys"}

The diversity of research topics and utilized methods is a competitive advantage of our BISE community and requires mutual respect and understanding amongst researchers. The vast majority of doctoral students in the BISE community intentionally seek management careers after finishing their doctorates. Consequently, for a long time doctoral work has emphasized creativity, analytical capabilities, and project management skills. Moreover, BISE researchers traditionally strive for "giant leaps" - to boldly answer relevant research questions nobody has ever asked before. In contrast, typical NAIS journals value "incremental articles [that] focus on a single question based on an assumption ground that has been established elsewhere" (Lyytinen et al. 2007, p. 320). With a strong focus solely on such NAIS publications doctoral students would become very specialized "mile deep/inch wide lonesome cowboys" without a connection to industry. This constitutes neither a role model for our doctoral students nor for a BISE professor in the classroom.

\subsubsection{Pragmatism Instead of Dogmatism to Drive Change Rather than Being Driven by Change}

To drive change in the community, researchers have to become successful players in their ecosystems - of course, without selling their souls and throwing their comparative advantages overboard. The reason is that only successful players have the opportunity to drive change from within, i.e., to establish criteria of success according to personal ideals. Trying to avoid adaptation by convincing the members of an ecosystem of its own value is a hopeless endeavor if one does not meet the criteria of success that govern the ecosystem. There is a reason why dogmatic missionaries end up in the cooking pot! For that same reason, any complaining-about-an-unfair-world or head-inthe-sand strategy is likewise condemned to fail.
So why does a BISE researcher have to act pragmatically and be concerned about rankings, citations, and impact factors? The answer is simple: It is demanded by the current ecosystem! To drive change, you first have to adapt to the ecosystem and become a successful player according to its criteria of success. It makes no sense to bury one's head in the sand and lament about the unpleasant situation. For example, JOURQUAL is mandatory for doctoral graduation and tenure at many universities in Germany. If young researchers (or the supervising professors) ignore JOURQUAL because of a dogmatic opinion, they will not pass many tenure committees that tend to simply decide based upon the number and "measured quality" of publications.

To sum up, all NAIS/BISE researchers should strive for a future where they can make strong contributions to theory and industry, can drive change from a position of strength according to their own ideals, have the opportunity to select from a diverse range of research topics and methods, and are free in their research. To achieve this, if members of the BISE community are involved in tenure committees or are reviewing articles, it is their responsibility to establish a multi-criteria rating system according to the community's standards and ideals. Solely staying within or striving into a narrow NAIS ecosystem is probably a comfortable strategy for few individual researchers. Advocating a separation strategy between NAIS and BISE, however, would be the work of narrow-minded separatists and endanger the future of the BISE community.

With the "freedom of research" being a part of several countries' constitutions, it is below a tenured scholar's dignity to let themselves be driven by economic or scientific ecosystems and not try to drive these themselves - the more they are in the better positions to do so. As a stronger personal position is achieved, one can and should increasingly debate such over-simplistic narrow criteria and argue for broader ones.

Hans Ulrich Buhl University of Augsburg

\section{Part Two}

In the second panel discussion (moderated by Robert Winter), the focus was not on controversial views on BISE's transformation. Since the positioning of our discipline and the diversity of its stakeholders seem to imply that scientific impact as well as practical impact need to be maximized, the question is 'how' rather than 'what'. The second panel therefore intended to present personal models that show how scientific impact and practice impact are not necessarily mutually exclusive, but that both impact dimensions can be combined to produce synergies. Peter 
Buxmann, Christine Legner, and Leena Suhl demonstrated by the example of their personal work strategies and experiences, what the specific challenges in their respective research communities are, where synergies can be exploited and where tradeoffs actually exist. While these examples are all from German-speaking countries, we believe that they are relevant also to BISE in general.

Peter Buxmann focuses on the necessity of start-ups and entrepreneurship to create practice impact from scientific innovation - and host that transfer in the scientific community. Christine Legner explains why IS researchers need to engage with practitioners, what issues arise in university-industry collaborations, and how engagement models should be designed to assure synergies between scientific and practical impact. Leena Suhl describes that, while innovative models and methods are published in scientific conferences and journals as long as they are general enough, their implementation in the form of software can create significant improvements in companies, so that scientific and practice impact can be successfully combined and create mutual benefit - e.g., by providing data for model/method validation and improvement.

\subsection{Entrepreneurship in the Digital Economy - Chances and Challenges for Research and Teaching in the Field of Information Systems}

Ever since Information Systems has established itself as a research discipline, the transfer of research results into practice has always guided scholars in that field. In this statement I will focus on the creation of intellectual property and the launch of start-ups on the basis of research results. Thereby, academic research and academic entrepreneurship do not eliminate, but rather complement each other, since research results can serve as a fruitful basis for launching and running young and innovative companies. Against that background, I work as the Head of the business incubator HIGHEST (Home of Innovation, GrowtH, EntrepreneurShip and Technology Management) at Darmstadt University of Technology in order to accelerate the formation of academic start-ups and thus support the regional economic development. Not surprisingly, one major focus is digital startups which obviously is in particular relevant for Information Systems.

In 2014, German start-ups in the digital sector and in the software industry amounted to about 50 percent of all new business formations including providers of SaaS, e-commerce, consumer mobile and web applications, to name a few (Buxmann et al. 2015). Due to trends in the digital industry such as Industry 4.0, Cloud Computing or Big Data, young entrepreneurs are confronted with multiple options to satisfy a growing demand for new solutions in the trend areas named. On the one hand, they can for example directly shape the industry by creating innovations that may change the course of recent developments. On the other hand, young firms can ride on ongoing trends by providing incremental advancements to small niche markets and specific customers. Overall, the ICT sector within Germany is amongst the largest concerning generated revenues and numbers of employees. Within the period 2011 through 2013, about 7000 start-ups belonging to the digital sector were founded (Bundesministerium für Wirtschaft und Energie 2014, pp. 16-17).

Despite a satisfactory development in Germany, the digital economy has not yet taken the lead regarding the introduction of digitalized revolutions on a global scale. Amongst the larger players, Germany ranks fifth after the United States, Southern Korea, the UK and Japan concerning market size, infrastructure and the usage of digitalized products and services (Bundesministerium für Wirtschaft und Energie 2014, p. 82). Thus, Germany is not the forerunner in the digital segment as compared to traditional industries such as the manufacturing of cars and machinery.

This argument is further exacerbated by the fact that Germany faces a negative trend in the total amount of firms founded (KfW Banking Group 2014, p. 2). This phenomenon may be rooted in several societal and regulatory conditions. These include for example that German entrepreneurs, in particular university graduates, face high opportunity costs regarding the decision to work for a large or midsize firm or rather be self-employed. Especially the relatively stable economic development of the German industry including a stable labor market may have a negative effect on the number of new firms founded. The additional risk involved when setting up a firm may simply seem too expensive if a larger or at least similar pay can be achieved while working for a corporation. In addition, the societal acceptance of failure with regard to founding a firm is, despite incremental changes in view, still rooted in peoples' minds. Compared with proactive and serial US or Israel founders who regard failure as an opportunity to learn, local founders see failure as something with a long lasting negative effect on one's professional career (Singer et al. 2014, p. 12).

Why is this topic highly relevant for our Information Systems discipline? First, researchers as well as students from the field of Information Systems are highly predestinated to become active in the field of startups and entrepreneurship in the digital economy. The main reason for this is that in contrast to traditional disciplines such as business administration, economics, computer science or engineering, the field of information systems provides a holistic and multidisciplinary perspective on both IT and business. And this combination of technological knowledge in conjunction with know-how in the field of business 
models is exactly what is needed to be successful in founding and running a startup in the digital world.

Second, recently in particular research in new business models has emerged as an important subject within the IS discipline (Veit et al. 2014, p. 45 ff). This trend is supported by an ever increasing number of conferences and journals which dedicate more weight and special issues towards that topic. Nevertheless, solid research on business models within a start-up context is still missing to a large extent. However, future research towards that topic, solely or primarily driven by IS, may provide insightful advancements that are both relevant from an economic and societal perspective. Against this background, teaching Entrepreneurship from an IS perspective could also be a fruitful basis for pushing startups in the digital world. Following the example of other countries and studies which have proved that academic education towards entrepreneurship has a positive influence on the number of businesses founded within the region, we should focus on sensitizing, qualifying and educating for entrepreneurship rather than simply educating entrepreneurship (Binks et al. 2006).

Overall, our foremost objective must be to enhance and further integrate the culture of entrepreneurship into our daily university routine in order to create a society of acceptance and of innovative business professionals to shape the 21 st century. IS, however, as mentioned above could be a trailblazer in this development for the digital industry. This change in perspective can be regarded as key in order to strengthen digital innovation through new ideas of young and creative minds.

\section{Peter Buxmann \\ Technical University of Darmstadt}

\subsection{Setting up University-Industry Collaboration (UIC) for Practical and Scientific Impact}

\subsubsection{Why Do IS Researchers Need to Engage with Practice?}

Complex IS phenomena cannot be studied in desk research alone and in isolation. As a researcher in business information systems, engaging with practitioners in the research process is a necessity not only to gain access to empirical data, but also to deepen one's understanding of the issues and solutions. The European IS community has a long tradition of conducting university-industry collaboration (UIC), which may take manifold forms and may support different research goals (Schubert et al. 2014). However, setting up these collaborations is not trivial. It is also perceived as being less likely to lead to high-impact publications in the top IS journals (see the debate on Why the Old World cannot publish by Lyytinen et al. 2007) and thus as being less compatible with tenure criteria. Against these negative perceptions, my experiences have been different: Throughout my academic career, I have worked on a large number of industry-funded research projects - ranging from consortium research, to government-funded projects or individual project support. All these projects can be classified as participatory research in which research activities were performed collaboratively "by a group of people containing academics and practitioners" (Schubert et al. 2014). The engagements were in different stages of the research process, from the identification of an interesting research question, to the research work, often with artifact development and demonstration, and the reflection on the findings. Many of the research questions I have addressed in academic publications have their origins in close practitioner cooperation. I have found that close interaction with practitioners may also act as differentiator in academic recruitment and may increase a journal submission's success rate - provided that the research results are produced and communicated in line with the prevailing scientific standards.

\subsubsection{Are Prevailing University-Industry Collaboration Models Good Enough?}

Independently from the specific collaboration model, engaging with practitioners in the research process adds complexity and bears certain risks:

- Project definition does not meet scientific standards: Engagements between universities and industry typically require contractual agreements and project plans that are negotiated upfront. Since funding decisions play an important role in these negotiations, the industry partners' expectations often dominate this phase. However, if the defined project goal and approach do not meet the scientific standards, the project is unlikely to produce impactful scientific results.

- High efforts for project setup and management: For researchers, industry collaboration requires establishing mutual understanding with professionals and coordinating the research activities with them over the entire research process. Depending on the setup, substantial efforts may be required and may distract the researcher from the production of research results. Another phenomenon is that researchers, especially those at Doctoral level, are often the most available and cheapest labor resource, and are therefore assigned the administrative tasks.

- Difficulties in addressing both practitioners and researchers: Even though practitioners and academics are often interested in the same phenomena, they have their specific questions, and may well also use a very 
different language to describe a phenomenon. Interacting with experienced practitioners and addressing their business pain points is therefore challenging, and researchers are in competition with consulting firms and analysts. On the academic side, some of the most interesting and relevant results for practice, such as reference models or conceptual frameworks, are hardly publishable in the leading academic journals, simply because they are too complex to be presented on a limited number of pages.

- Lack of control by researchers and discontinuity on the industry partners' side: A research project typically requires a longer timeframe than a pragmatic approach and more stability in conducting the project. Design science research, as an example, requires complete learning cycles of understanding, designing, demonstrating and evaluating an artifact. Whereas researchers are highly dependent on the involved partners for the entire project duration, changes that are not controllable by the researcher may happen in practice at any time during a project: Companies may change their priorities before the final research results are produced. Budget cuts or organizational changes may put the whole project at risk.

In view of these challenges, researchers need to consider the collaboration's organizational setup very carefully. If UIC happens ad hoc and merely focuses on practical problem-solving, its utility from the researchers' perspective is questionable. In my view, the prevailing collaboration models and forms between industry and practice leave room for improvement.

\subsubsection{How Does One Design Industry-University Collaboration for Practical and Scientific Impact?}

Over time, my experience with UIC has increased. The following guidelines helped me guarantee that my research projects create both practically and scientifically impactful results.

- Project charter and plan - Integrating the research goals and method: The methodological guidelines developed in the past few years, particularly for conducting design science (e.g. Action Design Research, Consortium Research) or qualitative research, are extremely valuable to ensure that research goals are met and research outcomes are produced according to scientific standards. These guidelines need to materialize in the UIC's project charter goals and plan. Particular emphasis should be given to the critical aspects of rigorous academic research, such as empirical data collection along the entire research process (e.g., trough measurements, observations, or interviews) and validation of findings.

- Research communication - Addressing different target audiences: Engaging with practice implies that researchers develop the ability to communicate research objectives and findings to different target audiences: the practitioner, who is driven by a specific business problem and needs to find suitable solutions, and the scientific community. The latter expects that the researcher anchors the phenomenon of interest in a specific scientific discourse and builds on prior concepts to analyze the problem and develop solutions. In UIC, translation between the different worlds becomes a crucial task and an essential skill for researchers. This implies not only documenting research results multiple times and in diverse forms, but also selecting appropriate communication channels to create practical and scientific impact. A professional magazine article, an executive education course or contributions to industry standardization initiatives help one to reach practitioners. However, the scientific impact will mostly depend on academic journal publications.

- Collaboration and role models - Shaping engagement models from a research perspective: In my experience, collaboration with multiple companies is preferable over collaboration with a single party, since it reduces dependency and improves the generalizability of research results. The relative success of $1: n$ or $n: m$ collaboration models is also underpinned by Schubert et al.'s (2014) survey. However, the resulting large and complex project settings also require very professional project management and more explicitly defined role models. Beyond the basic roles of industry (user) and university (researcher), additional parties, such as consulting firms or technology transfer specialists, assume specific roles in UICs for project management (facilitator) and for commercialization (multiplier). Thus, new institutional setups have emerged in the last years for advanced forms of UIC: Among them are Living Labs as Public-Private-People Partnerships (PPPP) for user-driven open innovation (http://www. openlivinglabs.eu/) or multilateral platforms, such as the Business Engineering Institute St. Gallen for consortium research (http://bei-sg.ch/). A more lightweight, yet very successful UIC model was piloted by Osterwalder and Pigneur for funding and co-creating the business model canvas with a global community of practitioners (http://businessmodelgeneration.com/ book).

To conclude, high-impact research requires well-designed UIC models. IS researchers should therefore place 
more emphasis on developing and improving their existing engagement models with practice to conform to scientific standards. In terms of outlook, we should be more creative in integrating new technologies into UIC to reach out to practice and to enable new ways of crowdfunding and coinnovation within a large community of professionals and researchers.

Christine Legner HEC Lausanne

\subsection{Research with Practical Impact and Scientific Impact in Business Information Systems}

Maintaining strong connections to real enterprises is essential to the discipline of Business and Information Systems Engineering. There are several ways to combine scientific impact with impact in practice. In the following, some examples in the area of decision support systems using quantitative methods are briefly described.

Problem-solving techniques and methods applied in the pursuit of improved decision-making and efficiency, such as optimization, simulation and data analysis, have been developed and scientifically published in operations research for several decades. In order to generate impact in practice, strong ties to computer science are necessary, and, simultaneously, a good knowledge of business processes and goals is needed. The goal from the point of view of the BISE discipline is thus to combine mathematical methods and informatics in order to develop decision support systems that improve business decision making and thus contribute to success of enterprises.

In the automotive industry, global supply chains with worldwide production and logistics systems are very complex and subject to dynamics in time as well as uncertain data. In joint workshops, researchers and practitioners have identified numerous topics that simultaneously imply a research challenge and - if solutions can be found - improve decision-making in practice. Such projects encompass, among other topics, modeling and optimizing production networks and processes on a strategic as well as tactical level, modeling inbound logistics networks and optimizing the transportation organization. Although uncertainties have been included into the models of many problems, a wide range of domains still lack stochastic or robust versions.

Many research projects in the area of traffic, especially schedule-based public transport of passenger and freight, have been initiated jointly by researchers and practitioners. Many examples can be found in airline traffic, railway networks, maritime systems and public bus transit. Diverse variants of mathematical optimization models are currently in use for rotation planning, fleet assignment, network design, line planning, crew scheduling, and so on. Research challenges are often given through special practical requirements that have not been considered in the scientific literature yet. Such requirements are typically present in several companies and thus imply a significant economical value for all companies of a certain given type.

In infrastructure systems, such as electricity and natural gas networks or water supply, similarly complex networks can be analyzed with decision-support techniques. Some examples are the gas purchasing and storing problem, water network optimization and optimization of energy production. New challenges have been introduced through the liberalization of infrastructure networks in the last years.

In order to evaluate the applicability in practice, the newly developed methods are ideally tested with practical data. Probably every researcher who needs data from industry for test purposes can tell a story about the problems in getting data useful for test runs: sometimes the approval process in the company takes very long, sometimes the data are technically difficult to extract or they contain missing elements and mistakes, or the management is just reluctant to give data for research purposes. Since relevant testing is essential for practical impact, researchers should not give up. Rather, researchers must work hard in convincing practitioners to release (anonymized) data for research purposes. It is important that commissions evaluating research acknowledge the hard work with practicerelevant data and the amount of time needed to get it analyzed appropriately. Often it would be much faster and easier to use existing artificial test data to write a research paper, but this would sacrifice the demonstration of practical relevance.

Ideally, a research project in operations-research-oriented BISE should have a twofold outcome: on one hand, the new models and methods are general enough to be published in scientific conferences and journals, and, on the other hand, software should be created that improves processes in practice. A university ideally provides a fruitful environment for the research work, where researchers working on different, but related, topics have the opportunity to discuss various approaches and support each other. Normally, a research project may produce a proof-of-concept and a research prototype, but it is not generally a goal of a university institute to develop software for use in production. If a research project is successful, the research results may be forwarded to the cooperation partner, who might let a software house develop it into a software system for the application area, or the university institute may cooperate with a spinoff company that brings the research results into practice first. Through scientific publications, the new methods and models are generally available to all other interested users for adoption. 
There are many ways to receive funding for practicerelevant scientific research: since all research results are published in scientific outlets, funding from the German Research Foundation (DFG) is possible for basic research questions. For open questions interesting to many companies, a consortium for public funding, typically by the BMBF, BMWI, or European Union, can be set up, and for more specific questions direct funding from industry might be a good solution.

To conclude, in order to maintain long-term relevance of our research, it is important for researchers not to lose contacts with the practice of BISE. The gap between existing theoretical/methodical results and the current requirements in practice should be the basis for high-level research activities that lead to innovative new solutions and systems, and simultaneously to high-level publications and ambitious new research results.

Leena Suhl University of Paderborn

\section{References}

Binks M, Starkey K, Mahon CL (2006) Entrepreneurship education and the business school. Technol Anal Strateg Manag 18(1):1-18. doi:10.1080/09537320500520411
Buhl HU (2013) Triple strategy revisited and upcoming changes. Bus Inf Syst Eng 5(6):373-376

Buhl HU, Fridgen G, Müller G, Röglinger M (2012a) On dinosaurs, measurement ideologists, separatists, and happy souls. Bus Inf Syst Eng 4(6):307-315

Buhl HU, Müller G, Fridgen G, Röglinger M (2012b) Business and information systems engineering: a complementary approach to information systems - what we can learn from the past and may conclude from present reflection on the future. J Assoc Inf Syst 13(4):236-253

Bundesministerium für Wirtschaft und Energie (BMWi) (2014) Monitoring-Report Digitale Wirtschaft 2014. Innovationstreiber IKT. Bundesministerium für Wirtschaft und Energie (BMWi), Berlin

Buxmann P, Diefenbach H, Hess T (2015) Die Softwareindustrie, 3rd edn. Springer, Heidelberg

KfW Banking Group (2014) KfW Gründungsmonitor 2014. Gründungstätigkeit wiederbelebt - Impuls aus dem Nebenerwerb. https://www.kfw.de/PDF/Download-Center/Konzernthemen/ Research/PDF-Dokumente-Gr\%C3\%BCndungsmonitor/KfWGr\%C3\%BCndungsmonitor-2014.pdf. Accessed 26 May 2015

Lyytinen K, Baskerville R, Iivari J, Te'eni D (2007) Why the old world cannot publish? Overcoming challenges in publishing high-impact IS research. Europ J Inf Syst 16(4):317-326

Schubert P, Kilian T, Bjørn-Andersen N (2014) I am an engaged scholar: A typology of IS researchers' engagement in research with industry. In: Proc CENTERIS 2014/ProjMAN 2014/HCIST 2014. Elsevier, Amsterdam, pp 138-149

Singer S, Amorós JE, Arreola DM (2014) Global Entrepreneurship Monitor. 2014 Global report. London Business School

Veit D, Clemons E, Benlian A, Buxmann P, Hess T, Spann M et al (2014) Business models - An information systems research agenda. Bus Inf Syst Eng 6(1):45-53 